\title{
Quantitative Trait Loci and Candidate Genes Associated with Fatty Acid Content of Watermelon Seed
}

\author{
Geoffrey Meru' ${ }^{1}$ and Cecilia McGregor \\ Department of Horticulture, University of Georgia, 1111 Plant Sciences Building, 120 Carlton Street, \\ Athens, GA 30602
}

\begin{abstract}
AdDitional InDEX wORDs. egusi, linoleic acid, oleic acid, palmitic acid, SOP, stearic acid
Abstract. Seed oil percentage (SOP) and fatty acid composition of watermelon (Citrullus lanatus) seeds are important traits in Africa, the Middle East, and Asia where the seeds provide a significant source of nutrition and income. Oil yield from watermelon seed exceeds $50 \%(\mathrm{w} / \mathrm{w})$ and is high in unsaturated fatty acids, a profile comparable to that of sunflower (Helianthus annuus) and soybean (Glycine max) oil. As a result of novel non-food uses of plant-derived oils, there is an increasing need for more sources of vegetable oil. To improve the nutritive value of watermelon seed and position watermelon as a potential oil crop, it is critical to understand the genetic factors associated with SOP and fatty acid composition. Although the fatty acid composition of watermelon seed is well documented, the underlying genetic basis has not yet been studied. Therefore, the current study aimed to elucidate the quality of watermelon seed oil and identify genomic regions and candidate genes associated with fatty acid composition. Seed from an $F_{2}$ population developed from a cross between an egusi type (PI 560023), known for its high SOP, and Strain II (PI 279261) was phenotyped for palmitic acid (16:0), stearic acid (18:0), oleic acid (18:1), and linoleic acid (18:2). Significant $(P<0.05)$ correlations were found between palmitic and oleic acid $(0.24)$, palmitic and linoleic acid $(-0.37)$, stearic and linoleic acid $(-0.21)$, and oleic and linoleic acid (-0.92). A total of eight quantitative trait loci (QTL) were associated with fatty acid composition with a QTL for oleic and linoleic acid colocalizing on chromosome (Chr) 6. Eighty genes involved in fatty biosynthesis including those modulating the ratio of saturated and unsaturated fatty acids were identified from the functionally annotated genes on the watermelon draft genome. Several fatty acid biosynthesis genes were found within and in close proximity to the QTL identified in this study. A gene (Cla013264) homolog to fatty acid elongase (FAE) was found within the 1.5-likelihood-odds (LOD) interval of the QTL for palmitic acid $\left(R^{2}=7.6 \%\right)$ on $\mathrm{Chr}$, whereas $\mathrm{Cla008157}$, a homolog to omega-3-fatty acid desaturase and Cla008263, a homolog to FAE, were identified within the 1.5-LOD interval of the QTL for palmitic acid $\left(R^{2}=\mathbf{2 4 . 7 \%}\right)$ on Chr 3. In addition, the QTL for palmitic acid on $\mathrm{Chr} 3$ was located $\approx 0.60 \mathrm{Mbp}$ from $\mathrm{Cla002633}$, a gene homolog to fatty acyl- [acyl carrier protein (ACP)] thioesterase B. A gene (Cla009335) homolog to ACP was found within the flanking markers of the QTL for oleic acid $\left(R^{2}=17.9 \%\right)$ and linoleic acid $\left(R^{2}=21.5 \%\right)$ on Chr 6, whereas Cla010780, a gene homolog to acyl-ACP desaturase was located within the QTL for stearic acid $\left(R^{2}=10.2 \%\right)$ on Chr 7. On Chr 8, another gene (Cla013862) homolog to acyl-ACP desaturase was found within the 1.5-LOD interval of the QTL for oleic acid $\left(R^{2}=13.5 \%\right)$. The genes identified in this study are possible candidates for the development of functional markers for application in marker-assisted selection for fatty acid composition in watermelon seed. To the best of our knowledge, this is the first study that aimed to elucidate genetic control of the fatty acid composition of watermelon seed.
\end{abstract}

Watermelon is an economically important crop of the Cucurbitaceae family, popular for its sweet edible flesh (Robinson and Decker-Walters, 1997). However, the seeds of watermelon provide a significant source of nutrition and income in other parts of the world including China (Zhang, 1996), Israel (Edelstein and Nerson, 2002), Iran (Baboli and Kordi, 2010), and Africa (Achigan-dako et al., 2008; Al-Khalifa, 1996; El-Adawy and Taha, 2001).

Watermelon seeds are rich in oils [greater than $50 \%$ (Baboli and Kordi, 2010)] and proteins [greater than 27\% (Al-Khalifa, 1996; Baboli and Kordi, 2010; Loukou et al., 2007)], thus playing a crucial role in supplementing the nutrients of the staple carbohydrate foods of the poor, who cannot afford animal-derived protein foods (Achu et al., 2005). The seed is manually dehulled to separate the kernels from the seedcoat and eaten raw, roasted, made into soup, or processed into cooking

Received for publication 6 Feb. 2014. Accepted for publication 28 Apr. 2014. This research was partially funded by the National Institute of Food and Agriculture (NIFA) Research and Education grant (GEO-2009-0418).

${ }^{1}$ Corresponding author. E-mail: merujeff@uga.edu. oil (Achigan-dako et al., 2008; Al-Khalifa, 1996). In addition, edible seeds of other cucurbits such as melon [Cucumeropsis mannii and Cucumis melo (Achigan-dako et al., 2008; Loukou et al., 2007)], squash [Cucurbita pepo (Idouraine et al., 1996)], pumpkin [C. pepo and Cucurbita moschata (Al-Khalifa, 1996)], and bottle gourd [Lagenaria siceraria (Achigan-dako et al., 2008; Achu et al., 2005)] are also nutritious and form a part of the diet in these communities.

The egusi watermelon (Citrullus lanatus ssp. mucosospermus var. egusi), which is easily identifiable by its unique fleshy, thick pericarp (Gusmini et al., 2004), is popularly cultivated for its edible seeds in Africa. The egusi seed is nutritious with a high SOP (Gusmini et al., 2004; Jarret and Levy, 2012; Prothro et al., 2012) and a high protein content (Gusmini et al., 2004). Whereas extensive research has been carried out toward improvement of the yield and quality of oil for the major oil crops such as soybean, sunflower, peanut (Arachis hypogaea), corn (Zea mays), and canola (Brassica napus), limited research has been done to improve these traits in cucurbit crops such as watermelon despite their agronomic and cultural importance (Loukou et al., 2007). The limited attention in research for cucurbits 
relative to staple crops has led to their underuse and classification as orphan crops (Achigan-dako et al., 2008; Baboli and Kordi, 2010; International Plant Genetic Resources Institute, 2002). Of the more than 500,000 known plant species, only 12 are currently exploited commercially to produce vegetable oil despite the increasing world demand (Baboli and Kordi, 2010; Mabaleha et al., 2007). Most of this demand is attributed to novel non-food uses including biofuel, oleochemicals, lubricants, pharmaceuticals, and cosmetics (Jarret and Levy, 2012; Panthee et al., 2006).

To improve the nutritive value of watermelon seed and establish watermelon as a potential oil crop, it is critical to understand the genetic factors associated with SOP and fatty acid composition. Prothro et al. (2012) elucidated the genetic factors associated with SOP in watermelon and identified four QTL associated with the trait. Among these, the egusi locus, which is also associated with the egusi seed phenotype, explained $83 \%$ of the phenotypic variation observed in SOP. Further studies have revealed that the high SOP in the egusi seed is the result of a high kernel percentage [KP (Jarret and Levy, 2012; Meru and McGregor, 2013)], and that seed size plays a role in SOP in watermelon (Meru and McGregor, 2013).

The type and ratio of fatty acids in a given vegetable oil determine its nutrition, flavor, shelf life, and its potential application (Brown et al., 1975; Panthee et al., 2006; Wassom et al., 2008; XinYou et al., 2011; Yang et al., 2010). Edible vegetable oils and seeds with low saturated fat content are desirable because they produce lower levels of low-density lipoproteins that have been linked with arteriosclerosis and heart-related ailments (Wassom et al., 2008). Therefore, plant breeders aim to reduce the levels of saturated fatty acids while increasing the levels of unsaturated fatty acids in oil crops. On the contrary, increased levels of saturated fats are desirable for the margarine and similar industries for the development of solid or semisolid fats without harmful chemical processes such as hydrogenation or transesterification (Ascherio and Willett, 1997, Panthee et al., 2006).

The four primary fatty acids in watermelon seed oil are palmitic acid (16:0), stearic acid (18:0), oleic acid (18:1), and linoleic acid (18:2) with linoleic acid being the most abundant (Al-Khalifa, 1996; Baboli and Kordi, 2010; El-Adawy and Taha, 2001; Giwa et al., 2010; Jarret and Levy, 2012; Loukou et al., 2007; Oluba et al., 2008). A study of fatty acid composition in watermelon genebank accessions by Jarret and Levy (2012) documented the range of different fatty acids in watermelon seeds [linoleic acid (45.37\% to $73 \%)$, oleic acid $(7.89 \%$ to $33.95 \%)$, stearic acid $(5.03 \%$ to $13.84 \%)$, palmitic acid $(9.68 \%$ to $14.38 \%)]$. The fatty acid composition in watermelon seed is similar to that found in other cucurbit crops. For instance, Al-Khalifa (1996) found similar levels of unsaturated fatty acids (oleic acid and linoleic acid) in watermelon (81.3\%) and pumpkin [C. pepo (80.1\%), C. moschata $(79.9 \%)]$. In comparison with the major oil crops, Baboli and Kordi (2010) found similar levels of palmitic acid in watermelon seed (11.36\%) and soybean (11\%) and similar levels of linoleic acid in watermelon seed (68.3\%) and sunflower (68\%). However, watermelon seed was lower in oleic acid $[13.25 \%$ ( sunflower $=18.6 \%$, soybean $=23.4 \%)]$ but higher in stearic acid $[7.04 \%$ (sunflower $=4.7 \%$; soybean $=4 \%$ )]

Although the fatty acid composition of watermelon seed oil is well documented, knowledge about the underlying genetic factors is lacking. The recent sequencing and functional annotation of the watermelon genome presents an opportunity for further research into the molecular mechanisms underlying economically important traits including fatty acid composition (Guo et al., 2013). Similar tools have recently been made available for melon (Blanca et al., 2012) and cucumber [Cucumis sativus (Huang et al., 2009)] through the sequencing and functional annotation of their respective genomes. Previous studies aimed at understanding the regulation of stearoyl-acyl carrier protein desaturation led to the isolation of a full-length cDNA clone of stearoyl-ACP protein desaturase in cucumber (Shanklin et al., 1991; Shanklin and Somerville, 1991). However, no DNA markers have been developed for cucurbit crops for application in marker-assisted selection (MAS) for improved oil quality.

The association of DNA markers with genes regulating fatty acid composition has enabled the application of MAS to accelerate breeding for improved oil quality in canola $(\mathrm{Hu}$ et al., 2006), spring turnip rape [Brassica rapa (Tanhuanpaa et al., 1998)], sunflower (Hongtrakul et al., 1998; Perez-Vich et al., 2002), soybean (Cardinal et al., 2007; Fehr, 2007; Pham et al., 2010; Zhang et al., 2008), and peanut (Barkley et al., 2010, 2013; Chu et al., 2009). As a step toward developing such genomic tools for watermelon, the current study aimed to identify genetic loci and candidate genes associated with fatty acid composition in watermelon seed for future application in MAS for improved oil quality. To our knowledge, this is the first effort to identify DNA markers linked to genomic regions associated with fatty acid composition in cucurbit seeds.

\section{Materials and Methods}

Plant material and genotyping. The $\mathrm{F}_{2}$ population $(\mathrm{n}=$ 142) from a cross between Strain II of the Japanese cultivar Yamato-cream [PI 279261 (normal seed type)] and an egusi type from Nigeria (PI 560023) used previously (Meru and McGregor, 2013; Prothro et al., 2012) to map loci controlling the egusi seed trait, SOP, and KP in watermelon was used in the present study. Single nucleotide polymorphism (SNP) assays were performed on the parents and progeny $\left(F_{2}, n=142\right)$ of the mapping population using an Illumina's GoldenGate SNP array and BeadStudio software (Illumina, San Diego, CA) as described in Sandlin et al. (2012). A genetic map was developed that included 357 SNP markers spanning 14 linkage groups (LGs) with an average gap of $4.2 \mathrm{cM}$ between markers (Sandlin et al., 2012).

FatTy ACID ANalysis. Phenotyping was carried out on seed derived from 142 open-pollinated $\mathrm{F}_{2}$ individuals (Prothro et al., 2012), the parental lines, and $F_{1}$. The 15 seeds from each $F_{2}$ plant and parental lines that were manually dehulled with a steel blade for the Meru and McGregor (2013) study were used for fatty acid analysis. The seed kernels from each sample were crushed with a mortar and pestle and $200 \mathrm{mg}$ of the powder was weighed and transferred into 2.2-mL 96-well plates (Fisher Scientific, Pittsburgh, PA). Fatty acid methyl esters (FAMEs) were prepared using the standard method for analyses of fatty acid composition in fats and oils recommended by the American Oil Chemist's Society [Ce 1-62 (American Oil Chemist's Society, 2009)]. To extract oil from the samples, $2 \mathrm{~mL}$ of hexane (Fisher Scientific) was added to each well followed by incubation at room temperature $\left(25^{\circ} \mathrm{C}\right)$ for $15 \mathrm{~min}$. The supernatant $(0.5 \mathrm{~mL})$ from each sample was transferred to a new 96-well plate and evaporated to dryness with a stream of 
$\mathrm{N}_{2}$ at $50{ }^{\circ} \mathrm{C}$ on a 96 -well evaporator. To each well, $0.2 \mathrm{~mL}$ of ethyl ether (BDH, Poole, U.K.) was added to solubilize the lipids followed by the addition of $0.2 \mathrm{~mL} 0.1 \mathrm{M} \mathrm{KOH}$ and incubation at $50^{\circ} \mathrm{C}$ for $10 \mathrm{~min}$ to convert the lipids into FAMEs. The methylation reactions were stopped by adding $0.2 \mathrm{~mL}$ of $0.15 \mathrm{M} \mathrm{HCl}$. The samples were incubated at room temperature for $15 \mathrm{~min}$, and an aliquot $(0.5 \mathrm{~mL})$ of the organic layer containing FAMEs was transferred to 2 -mL autosampler vials (Fisher Scientific) for gas chromatography (GC) analysis. The FAMEs were separated by injecting $1 \mu \mathrm{L}$ of sample onto a GC column (DB-23) in a gas chromatograph (6890 Series; Agilent, Wilmington, DE) equipped with an autosampler carousel. A standard (15A; Nu-Control Prep, Elysian, MN) with known concentrations for palmitic (16:0), stearic (18:0), oleic (18:1), and linoleic (18:2) acids was used to identify peaks. The profile for the fatty acids was estimated from chromatograms using ChemStation Software (Agilent). Fatty acid extraction was carried out twice from different portions of the original ground sample and the average value for each line used in the data analysis.

Correlations, mean separation, and QTL detection. Pearson correlations between the values of the phenotypic traits were calculated using JMP (Version 11; SAS Institute, Cary, NC). The values for SOP for the population were previously determined by Prothro et al. (2012), whereas those of seed size (seed weight) were determined by Meru and McGregor (2013). Student's $t$ test was performed in JMP to identify differences in the means of the various fatty acids in normal $(n=100)$ and egusi $(n=42)$ seed subpopulations.

The fatty acid values were arcsine square root-transformed before QTL analysis because they are expressed as a proportion of total fatty acids in the oil (Wills et al., 2010). Composite interval mapping (CIM) was used to detect QTL with a 5-cM window in WinQTL Cartographer Version 2.5 (Wang et al., 2011a). The standard model (Model 6) with a walk speed of $1 \mathrm{cM}$ was used for CIM analysis and the population type was designated as "RF3" (Wang et al., 2011a). Statistical significance of a QTL was determined by likelihood-odds thresholds set by 1000 permutations $[\alpha=0.05$ (Churchill and Doerge, 1994)]. QTL detected on the same LG were not considered different unless they were separated by at least $20 \mathrm{cM}$ (Ravi et al., 2011). All LGs and QTL were visualized using MapChart 2.2 (Voorrips, 2002).

FATTY ACID BIOSYNTHESIS GENES IN WATERMELON. The genes involved in fatty acid biosynthesis in watermelon were determined by comparing annotated genes in the watermelon draft genome (Guo et al., 2013; International Cucurbits Genomics Initiative, 2012) with genes reported to be involved in fatty acid biosynthesis for other crops (Byfield et al., 2006; Cahoon et al., 1994; Cardinal et al., 2007; Kachroo et al., 2008; Li et al., 2010).
Candidate Genes. Markers flanking the 1.5 -LOD $[\approx 95 \%$ confidence interval (Silva et al., 2012)] interval for all the QTL were identified on the linkage map and their corresponding positions on the watermelon physical map (Guo et al., 2013) determined. The regions between the flanking markers were then inspected for genes in the fatty acid biosynthesis pathway.

\section{Results and Discussion}

Phenotypic analysis of traits. Linoleic acid was the predominant fatty acid detected. The levels of palmitic acid and linoleic acid in the Strain II parent $(9.36 \%$ and $70.72 \%$, respectively) were higher than in the egusi parent $(8.50 \%$ and $61.15 \%$, respectively), whereas those of stearic acid and oleic acid in the egusi parent $(7.92 \%$ and $22.42 \%$, respectively) were higher than in Strain II (5.59\% and $14.33 \%$, respectively) (Table 1). These results are similar to those reported by Jarret and Levy (2012) for egusi (palmitic $=9.68 \%$ to $12.82 \%$, stearic $=8.63 \%$ to $13.84 \%$, oleic $=8.14 \%$ to $17.26 \%$, linoleic $=58.95 \%$ to $71.10 \%$ ) and for the seeds of edible watermelon (palmitic $=9.68 \%$ to $14.38 \%$, stearic $=5.03 \%$ to $11.52 \%$, oleic $=7.89 \%$ to $25.67 \%$, linoleic $=48.7 \%$ to $73 \%$ ). In comparison with the major oil crops, the degree of unsaturation (oleic acid and linoleic acid) found in this study for watermelon (Strain II $=85.1 \%$, egusi $=$ $83.6 \%$ ) was similar to that of soybean $(84.4 \%)$ and sunflower $(88.6 \%)$ (Baboli and Kordi, 2010).

Extraction of crude oil from watermelon seeds for subsistence use is common in West Africa (Achigan-dako et al., 2008; Jarret and Levy, 2012; Oluba et al., 2008). However, this oil may have a low shelf life and less stability at high cooking temperature as a result of high linoleic acid content, which is highly oxidative. High levels of linoleic acid content (57\%) in soybean has led to breeding efforts to decrease the content of this fatty acid in favor of oleic acid, which is more stable at high cooking temperature (Baboli and Kordi, 2010; Lee et al., 2007). Linoleic acid is more oxidative as a result of the presence of two double bonds as opposed to oleic acid, which has a single double bond (Lee et al., 2007). For watermelon seed to be exploited commercially for the production of cooking oil, it is necessary to breed for reduced levels of linoleic acid and increased levels of oleic acid to improve its stability and shelf life. From the study on watermelon genebank accessions by Jarret and Levy (2012), it is clear that natural variation exists in oleic acid (7.89\% to $33.95 \%)$ and linoleic acid (45.37\% to $73 \%)$ and can be exploited in breeding to produce cultivars of high oleic acid and lower linoleic acid. Adoption of watermelon as a minor oil crop would improve farmers' earnings while concurrently reducing the amount of solid waste resulting from the disposal of watermelon seeds (Baboli and Kordi, 2010; El-Adawy and Taha, 2001).

Table 1. Watermelon seed oil fatty acid composition of palmitic acid (16:0), stearic acid (18:0), oleic acid (18:1), and linoleic acid (18:2) in Strain II (PI 279261), egusi (PI 560023), $\mathrm{F}_{1}$, and $\mathrm{F}_{2}$ population $(\mathrm{n}=142)$ derived from a cross between Strain II and egusi.

\begin{tabular}{|c|c|c|c|c|c|c|c|c|}
\hline & \multirow{2}{*}{\multicolumn{2}{|c|}{ Strain II }} & \multirow[b]{2}{*}{$\mathrm{F}_{1}$} & \multicolumn{5}{|c|}{$\mathrm{F}_{2}$ population } \\
\hline & & & & \multirow{2}{*}{\multicolumn{5}{|c|}{$\begin{array}{l}\text { Mean } \\
\text { atty acid composition (\% by wt) }\end{array}$}} \\
\hline Fatty acid & & & & & & & & \\
\hline Palmitic & 9.36 & 8.50 & 10.95 & 10.57 & 0.58 & 3.01 & 9.07 & 12.08 \\
\hline Oleic & 14.33 & 22.42 & 18.50 & 18.8 & 3.03 & 16.81 & 12.46 & 29.28 \\
\hline Linoleic & 70.72 & 61.15 & 62.48 & 62.12 & 3.25 & 19.63 & 50.65 & 70.28 \\
\hline
\end{tabular}


Within the population, palmitic acid ranged from $9.07 \%$ to $12.08 \%$, stearic acid from $4.33 \%$ to $11.94 \%$, oleic acid from $12.46 \%$ to $29.28 \%$, and linoleic acid from $50.65 \%$ to $70.28 \%$ (Table 1). Transgressive segregation was observed in one direction for palmitic acid and linoleic acid and in both directions for stearic acid and oleic acid whereby the progeny had trait values outside the range of the parents. Transgressive segregation is primarily associated with antagonistic additive effects (Rieseberg et al., 1999). Linoleic acid was found to be significantly $(P<0.05)$ negatively correlated to palmitic $(-0.37)$, stearic $(-0.21)$, and oleic $(-0.92)$ fatty acids. However, palmitic acid was significantly positively correlated $(0.24)$ to oleic acid (Table 2). Oyenuga and Fetuga (1975) found a significant positive correlation between palmitic acid and oleic acid but a negative correlation between palmitic acid and linoleic acid in watermelon. On the contrary, Jarret and Levy (2012) did not find significant correlations between these fatty acids in watermelon. In wheat (Triticum aestivum), Wang et al. (2011b) found linoleic acid to be significantly negatively correlated to palmitic, stearic, oleic, and linolenic acids. Palmitic acid was the only trait significantly correlated with SOP (-0.22) (Table 2). This relationship may explain the observation in egusi watermelon whose seeds have high SOP (Gusmini et al., 2004; Jarret and Levy, 2012; Meru and McGregor, 2013; Prothro et al., 2012) but lower levels of palmitic acid relative to other watermelon types (Jarret and Levy, 2012). In the current study, significant differences $(P<$ 0.05 ) were found between palmitic acid levels in normal (low SOP) and egusi (high SOP) seeds further supporting this relationship. However, no unique QTL for palmitic acid were identified when mapping normal and egusi seed separately (data not shown). In canola, Zhao et al. (2008) found a negative correlation between oil content and palmitic acid $(-0.34)$, whereas in soybean, a negative correlation $(-0.53)$ between linoleic acid and oil content has been documented ( $\mathrm{Li}$ et al., 2011). No significant differences were found between egusi and normal seeds in the population for the levels of stearic acid, oleic acid, and linoleic acid (data not shown). Seed weight was significantly positively correlated with oleic acid $(0.27)$ but significantly negatively correlated with linoleic acid $(-0.24)$. These results are similar to those obtained in soybean by Liu et al. (1995) who found a positive correlation between seed size and oleic acid but a negative correlation between seed size and linoleic acid.

Detection of QTL. Genetic analysis detected a total of eight QTL on Chr 2, 3, 5, 6, 7, and 8, three each for palmitic acid and oleic acid and one each for stearic acid and linoleic acid (Fig. 1; Table 3). The QTL for oleic acid $\left(R^{2}=17.9 \%\right)$ colocalized with a QTL for linoleic acid $\left(R^{2}=21.5 \%\right)$ on $\mathrm{Chr}$

Table 2. Pearson correlations for fatty acids, seed oil percentage [SOP (Prothro et al., 2012)], and seed weight (Meru and McGregor, 2013) in the Strain II (PI 279261) $\times$ egusi (PI 560023) $\mathrm{F}_{2}$ watermelon population $(\mathrm{n}=142)$.

\begin{tabular}{lccccc}
\hline Trait & SOP & Seed wt & $\begin{array}{c}\text { Palmitic } \\
\text { acid }\end{array}$ & $\begin{array}{c}\text { Stearic } \\
\text { acid }\end{array}$ & $\begin{array}{c}\text { Oleic } \\
\text { acid }\end{array}$ \\
\hline Palmitic acid & $-0.22^{*}$ & 0.01 & & & \\
Stearic acid & 0.11 & 0.02 & -0.01 & & \\
Oleic acid & 0.12 & $0.27^{*}$ & $0.24^{*}$ & -0.15 & \\
Linoleic acid & -0.12 & $-0.24^{*}$ & $-0.37^{*}$ & $-0.21^{*}$ & $-0.92^{*}$ \\
\hline
\end{tabular}

*Significant at $P<0.05$.
6. Colocalization of the two traits can be expected because of the high negative correlation between the traits $(-0.92)$ (Table 2 ), which is consistent with the fact that the two fatty acids share a common pathway where desaturation of oleic acid by omega6 fatty acid desaturase-2 (FAD2) yields linoleic acid in plants (Bachlava et al., 2009; Liu et al., 2011; Sharma et al., 2002; Yu et al., 2008). Colocalization of QTL for oleic acid and linoleic acid is common in crops including corn (Wassom et al., 2008; Yang et al., 2010), wheat (Wang et al., 2011b), and soybean (Panthee et al., 2006).

Colocalization was also observed between the QTL for oleic acid and linoleic acid on Chr 6 and QTL for seed size (seed weight) in normal seed identified by Meru and McGregor (2013). These results might explain the significant correlation observed between seed size and the two fatty acids in the current study (Table 2). QTL for oleic acid were also detected on $\operatorname{Chr} 2\left(R^{2}=10.7 \%\right)$ and $\mathrm{Chr} 8\left(R^{2}=13.5 \%\right)$. QTL for palmitic acid were identified on Chr $2\left(R^{2}=7.6 \%\right)$, Chr $3\left(R^{2}=24.7 \%\right)$, and Chr $5\left(R^{2}=12.7 \%\right)$, whereas a single QTL for stearic acid was identified on $\mathrm{Chr} 7\left(R^{2}=10.2 \%\right)$ (Fig. 1; Table 3).

FATTY ACID BIOSYNTHESIS GENES IN WATERMELON. An examination of the functionally annotated genes in the watermelon draft genome (Guo et al., 2013) revealed 80 genes involved in fatty acid biosynthesis (Supplemental Table 1). Of particular interest among the identified genes are those central in regulating the ratio of saturated (palmitic acid and stearic acid) and unsaturated (oleic acid and linoleic acid) fatty acids. This ratio is important because it determines the potential application of vegetable oils (Brown et al., 1975; Panthee et al., 2006; Wassom et al., 2008; XinYou et al., 2011; Yang et al., 2010). The fatty acyl-ACP thioesterase-B (FATB) regulates the amount of saturated fatty acids by hydrolyzing the acyl group from saturated-ACP (16:0-ACP and 18:0-ACP) to release free saturated fatty acids (Barker et al., 2007; Bonaventure et al., 2003). In watermelon, five genes potentially encoding this enzyme were identified on several chromosomes. Similarly, five genes are predicted to encode FATB genes in peanut (Yin et al., 2013) and one each in arabidopsis [Arabidopsis thaliana (Barker et al., 2007; Bonaventure et al., 2003)] and jatropha [Jatropha curcas (Natarajan and Parani, 2011)]. In soybean, several low-palmitic acid cultivars have been developed by mutagenesis (ethyl methanesulfonate and N-nitroso-N-methyl urea and X-radiation) and molecular analysis of these cultivars has revealed mutation in various FATB genes (Cardinal et al., 2007).

The number of genes potentially encoding acyl-ACP desaturases in watermelon (12 genes) was higher than that in peanut [eight genes (Yin et al., 2013)] and jatropha [four genes (Natarajan and Parani, 2011)]. Acyl-ACP desaturases are soluble enzymes that introduce double bonds into acyl-ACPs in oxygen-dependent reactions to form monounsaturated fatty acids and hence modulate the ratio of saturated and unsaturated fatty acids (Guy et al., 2011). For example, the stearoyl-ACP protein desaturase (SADP) introduces a double bond at $\mathrm{C}_{9}$ in stearic acid (18:0) to form oleic acid (18:1). In soybean, mutations in the SADP have been sought to increase the levels of stearic acid (and reduce the levels of oleic acid) in soybean oil to decrease the cost of hydrogenation in the food processing industry (Byfield et al., 2006). Although stearic acid is a saturated fatty acid, it does not increase cholesterol levels in humans and thus does not pose a health risk in contrast to palmitic acid (Ruddle et al., 2013). Most of the high stearic acid 

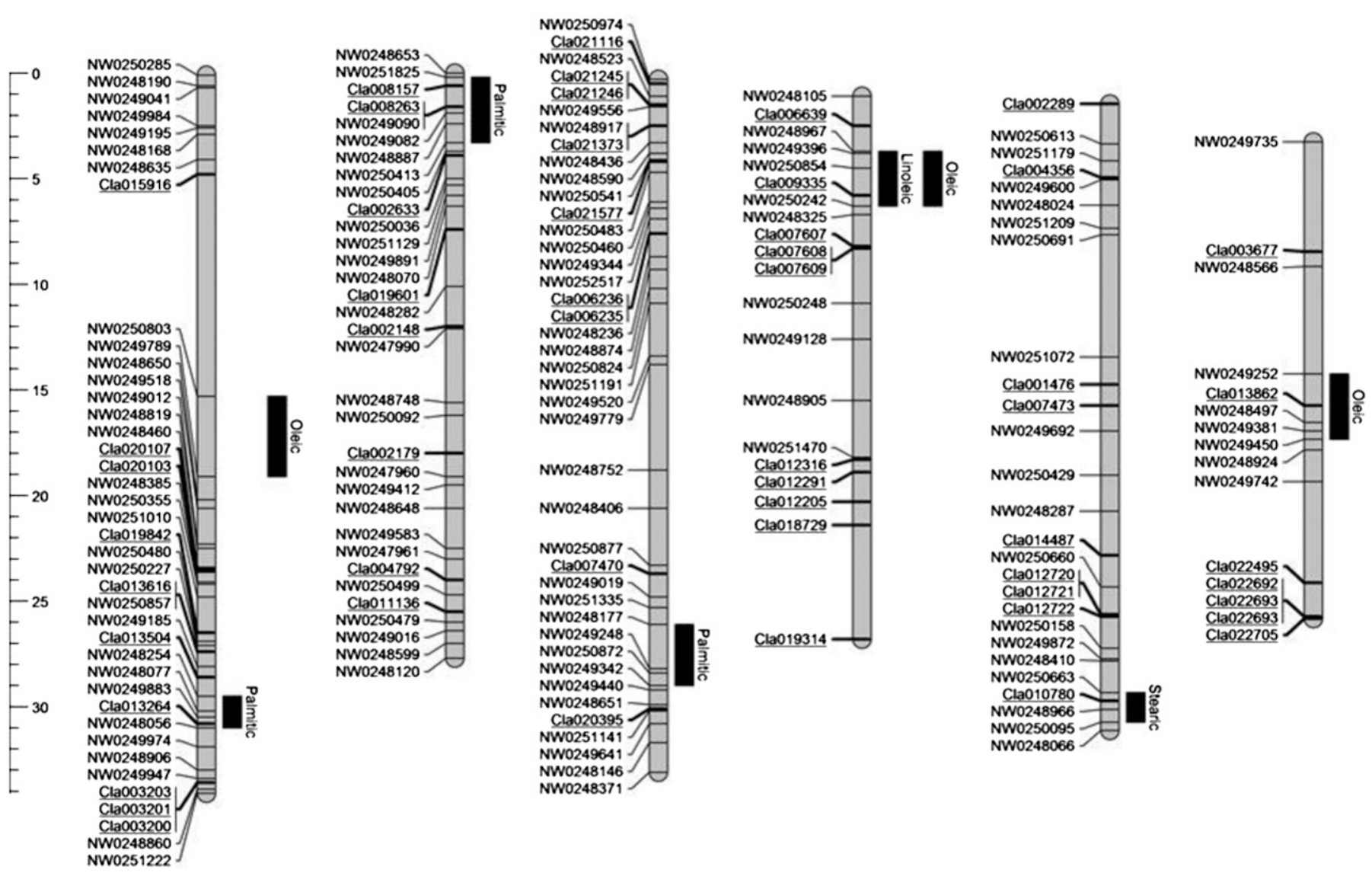

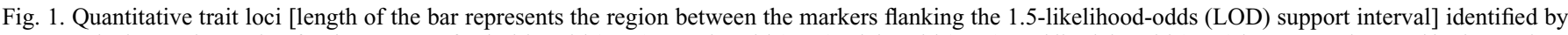
composite interval mapping for the content of palmitic acid (16:0), stearic acid (18:0), oleic acid (18:1), and linoleic acid (18:2) in watermelon seed in the Strain II (PI 279261) $\times$ egusi (PI 560023) watermelon population. The genes involved in the fatty acid biosynthesis pathway are underlined. Figure generated using MapChart Version 2.2 (Voorrips, 2002).

soybean germplasm lines have been developed using mutagenesis targeting SADP (Ruddle et al., 2013), although a natural mutation in the gene has also been reported in one cultivar (Byfield et al., 2006; Ruddle et al., 2013).

Increased levels of oleic acid and concomitant reduction in levels of linoleic acid have been achieved in oil crops by targeting FAD2 that converts oleic acid into linoleic acid by inserting a double bond at $\mathrm{C}_{12}$ (Heppard et al., 1996; Yu et al., 2008). High oleic acid peanut cultivars have been obtained both through radiation-induced mutagenesis and exploitation of natural mutations in FAD2 (Yu et al., 2008). Four genes potentially encoding FAD2 were identified in watermelon on Chr 2, 6, and 11, a number lower than that of FAD2 in peanut (13) (Yin et al., 2013).

Candidate Genes. The genes Cla013264 (E-value: 2E-200) and Cla008263 (E-value: 2E-195) homologs to 3-ketoacylCoA synthase in Populus trichocarpa (Supplemental Table 1) were found within the 1.5-LOD interval of the QTL for palmitic acid on $\operatorname{Chr} 2\left(R^{2}=7.6 \%\right)$ and $\operatorname{Chr} 3\left(R^{2}=24.7 \%\right)$, respectively. 3-ketoacyl-CoA synthase is a subunit of fatty acid elongase (FAE) complex that condenses acyl-CoA with malonyl-CoA as the first step in the synthesis of very long fatty acids (Bach et al., 2008; Bach and Faure, 2010; Barret et al., 1998). The association of this QTL with variation in palmitic acid may be explained by the use of palmitic acid to form palmitoyl-CoA, which is used as a substrate by 3-ketoacyl-CoA synthase (Bach et al., 2008; Bach and Faure, 2010). In canola, FAE is associated with variation in erucic acid (22:1) and is targeted in breeding for low erucic acid (cooking oil) and high erucic acid (industrial applications) canola cultivars (Barret et al., 1998; Fourmann et al., 1998).

In addition, a gene (Cla008157) homolog (E-value: 1E-136) to omega-3 desaturase (FAD3) in Betula pendula (Supplemental Table 1) was found within the flanking markers of the QTL for palmitic acid on Chr 3. FAD3 catalyzes the insertion of a double bond into linoleic acid to yield linolenic acid and is a central target for breeders in manipulating the levels of linolenic acid, which is undesirable in soybean oil (Anai et al., 2005). Interestingly, Cla002633, a homolog (E-value: 4E-61) to the FATB gene in Ricinus communis (Supplemental Table 1), is just outside $(\approx 0.60 \mathrm{Mbp}$ from NW0250413) the 1.5-LOD interval of the palmitic acid QTL on Chr 3. Fatty acid thioesterase B hydrolyzes the acyl group from palmitoyl-ACP to release free palmitic acid and ACP (Bonaventure et al., 2003; Cardinal et al., 2007). A natural deletion in the FATB gene of soybean was shown to result in reduced palmitic acid levels (Cardinal et al., 2007). Similarly, reduction in the levels of palmitic acid has been reported in chemical and induced mutants that resulted in perturbation of FATB isoforms in soybean (Cardinal et al., 2007). 


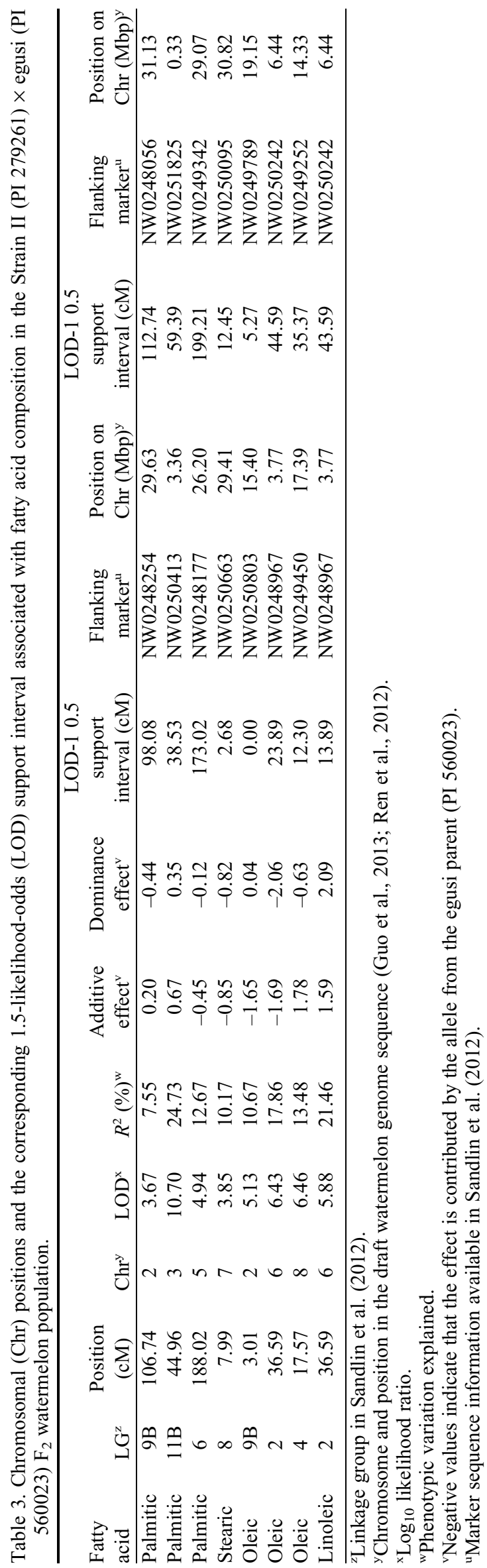


The gene (Cla009335) homolog (E-value: 1E-26) to ACP in Fragaria vesca (Supplemental Table 1) was found within the flanking markers of the QTL for oleic acid and linoleic acid on Chr 6. ACPs are acidic proteins involved in de novo fatty acid synthesis, acyl chain modification, and chain-length termination during fatty acid biosynthesis (Li et al., 2010).

A gene (Cla010780), homolog (E-value: 6E-46) to the SADP gene in Picea glauca, and Cla013862, a homolog (E-value: 3E-173) to the SADP gene in $R$. communis, were located within the flanking markers of QTL for stearic acid on Chr 7 and oleic acid on Chr 8, respectively. The SADP gene catalyzes the conversion of stearic acid to oleic acid (Barker et al., 2007; Byfield et al., 2006) and may explain why the gene is associated with both the QTL for stearic acid and oleic acid in watermelon seed. In soybean, silencing of SADP resulted in a 3.6-fold reduction in oleic acid levels and a 6-fold increase in stearic acid levels when compared with the wild type (Kachroo et al., 2008), whereas in Thunbergia alata, overexpression of the gene led to accumulation of oleic acid (Cahoon et al., 1994). Physiologically, alteration in the function of SADP in plants results in changes in membrane integrity and fluidity, which in turn affect a plant's ability to acclimatize to cold or activate the salicylic-dependent pathogen defense pathway (Kachroo et al., 2008).

The genes identified in this study are possible candidates for the development of functional markers for application in MAS for improved oil quality in watermelon seed. The main QTL for palmitic acid on Chr $3\left(R^{2}=24.7 \%\right)$ and that for oleic acid $\left(R^{2}=\right.$ $17.9 \%)$ and linoleic acid $\left(R^{2}=21.5 \%\right)$ on Chr 6 present possible targets in MAS for manipulating the levels of saturated and unsaturated fatty acids in watermelon seed. In the major oil crops, the key genes in the fatty acid biosynthesis pathway have been cloned and well characterized (Barkley et al., 2013; Byfield et al., 2006; Cardinal et al., 2007). Availability of these genomic tools in these crops has led to the development of functional markers and identification of markers tightly linked to key fatty acid biosynthesis genes. Allele specific primers for the FAD2 gene have been developed for canola ( $\mathrm{Hu}$ et al., 2006), spring turnip rape (Tanhuanpaa et al., 1998), sunflower (Hongtrakul et al., 1998; Perez-Vich et al., 2002), soybean (Pham et al., 2010), and peanut (Barkley et al., 2010, 2013; Chu et al., 2009). Similarly, candidate genes for SADP (Pham et al., 2010; Zhang et al., 2008) and FATB (Cardinal et al., 2007; Fehr, 2007) have been tagged with molecular markers in soybean.

In breeding for oil quality in watermelon seed, targeting genes encoding FATB, SADP, and FAD2 would be logical because these enzymes are central in determining the fatty acid composition in oil crops. Given the variation in fatty acid composition reported for watermelon genebank accessions by Jarret and Levy (2012) [linoleic acid (45.37\% to 73\%), oleic acid $(7.89 \%$ to $33.95 \%)$, stearic acid (5.03\% to $13.84 \%)$, palmitic acid $(9.68 \%$ to $14.38 \%)$ ], conventional breeding can be used to develop watermelon cultivars of superior oil quality by selection of appropriate combinations of the naturally occurring alleles in the gene pool.

\section{Literature Cited}

Achigan-dako, E.G., R. Fagbemissi, H.T. Avohou, R.S. Vodouhe, O. Coulibaly, and A. Ahanchede. 2008. Importance and practices of egusi crops [Citrullus Lanatus (Thunb.) Matsum. \& Nakai, Cucumeropsis mannii Naudin and Lagenaria siceraria (Molina) Standl. cv. 'Aklamkpa']) in sociolinguistic areas in Benin. Biotechnol. Agron. Soc. Environ. 12:393-403.

Achu, M.B., E. Fokou, C. Tchiégang, M. Fotso, and F.M. Tchouanguep. 2005. Nutritive value of some Cucurbitaceae oilseeds from different regions in Cameroon. Afr. J. Biotechnol. 4:1329-1334.

Al-Khalifa, A. 1996. Physicochemical characteristics, fatty acid composition, and lipoxygenase activity of crude pumpkin and melon seed oils. J. Agr. Food Chem. 44:964-966.

American Oil Chemist's Society. 2009. Fatty acid composition by packed column gas chromatography. 17 Oct. 2013. <http:// www.aocs.org/tech/onlinemethods/>.

Anai, T., T. Yamada, T. Kinoshita, S.M. Rahman, and Y. Takagi. 2005. Identification of corresponding genes for three low-linolenic acid mutants and elucidation of their contribution to fatty acid biosynthesis in soybean seed. Plant Sci. 168:1615-1623.

Ascherio, A. and W.C. Willett. 1997. Health effects of trans fatty acids. Amer. J. Clin. Nutr. 66:1006-1010.

Baboli, Z.M. and A.A.S. Kordi. 2010. Characteristics and composition of watermelon seed oil and solvent extraction parameters effects. J. Amer. Oil Chem. Soc. 87:667-671.

Bach, L. and J. Faure. 2010. Role of very-long-chain fatty acids in plant development, when chain length does matter. C. R. Biol. 333:361-370.

Bach, L., L.V. Michaelson, R. Haslam, Y. Bellec, L. Gissot, J. Marion, M. Da Costa, J. Boutin Miquel, M., F. Tellier, F. Domergue, J.E. Markham, F. Beaudoin, J.A. Napier, and J. Faure. 2008. The verylong-chain hydroxy fatty acyl-CoA dehydratase PASTICCINO2 is essential and limiting for plant development. Proc. Natl. Acad. Sci. USA 105:14727-14731.

Bachlava, E., R.E. Dewey, J.W. Burton, and A.J. Cardinal. 2009. Mapping candidate genes for oleate biosynthesis and their association with unsaturated fatty acid seed content in soybean. Mol. Breed. 23:337-347.

Barker, G.C., T.R. Larson, I.A. Graham, J.R. Lynn, and G.J. King. 2007. Novel insights into seed fatty acid synthesis and modification pathways from genetic diversity and quantitative trait loci analysis of the brassica C genome. Plant Physiol. 144:1827-1842.

Barkley, N.A., K.D.C. Chamberlin, M.L. Wang, and R.N. Pittman. 2010. Development of a real-time PCR genotyping assay to identify high oleic acid peanuts (Arachis hypogaea L.). Mol. Breed. 25:541548.

Barkley, N.A., T.G. Isleib, M.L. Wang, and R.N. Pittman. 2013. Genotypic effect of ahFAD2 on fatty acid profiles in six segregating peanut (Arachis hypogaea L) populations. BMC Genet. 14:62.

Barret, P., R. Delourme, M. Renard, F. Domergue, R. Lessire, M. Delseny, and T.J. Roscoe. 1998. A rapeseed FAE1 gene is linked to the $E 1$ locus associated with variation in the content of erucic acid. Theor. Appl. Genet. 96:177-186.

Blanca, J.C.E., P. Ziarsolo, D. Pérez, V. Fernández-Pedrosa, C. Collado, R. Rodríguez de Pablos, A. Ballester, C. Roig, J. Cañizares, and B. Picó. 2012. Transcriptome sequencing for SNP discovery across Cucumis melo. BMC Genomics 13:280.

Bonaventure, G., J.J. Salas, M.R. Pollard, and J.B. Ohlrogge. 2003. Disruption of the FATB gene in arabidopsis demonstrates an essential role of saturated fatty acids in plant growth. Plant Cell 15:1020-1033.

Brown, D.F., C.M. Cater, K.F. Mattil, and J.G. Darroch. 1975. Effect of variety, growing location and their interaction on the fatty acid composition of peanuts. J. Food Sci. 40:1055-1060.

Byfield, G.E., H. Xue, and R.G. Upchurch. 2006. Two genes from soybean encoding soluble stearoyl-ACP desaturases. Crop Sci. 46:840-846.

Cahoon, E.B., C.K. Becker, J. Shanklin, and J.B. Ohlrogge. 1994. cDNAs for isoforms of the stearoyl-acyl carrier protein desaturase from Thunbergia alata endosperm. Plant Physiol. 106:807-808.

Cardinal, A.J., J.W. Burton, A.M. Camacho-Roger, J.H. Yang, R.F. Wilson, and R.E. Dewey. 2007. Molecular analysis of soybean lines with low palmitic acid content in the seed oil. Crop Sci. 47:304-310. 
Chu, Y., C.C. Holbrook, and P. Ozias-Akins. 2009. Two alleles of ahFAD2B control the high oleic acid trait in cultivated peanut. Crop Sci. 49:2029-2036.

Churchill, G.A. and R.W. Doerge. 1994. Empirical threshold values for quantitative trait mapping. Genetics 138:963-971.

Edelstein, M. and H. Nerson. 2002. Genotype and plant density affect watermelon grown for seed consumption. HortScience 37:981-983. El-Adawy, T.A. and K.M. Taha. 2001. Characteristics and composition of watermelon, pumpkin, and paprika seed oils and flours. J. Agr. Food Chem. 49:1253-1259.

Fehr, W.R. 2007. Breeding for modified fatty acid composition in soybean. Crop Sci. 47:S72-S87.

Fourmann, M., P. Barret, M. Renard, G. Pelletier, R. Delourme, and D. Brunel. 1998. The two genes homologous to arabidopsis FAE1 cosegregate with the two loci governing erucic acid content in Brassica napus. Theor. Appl. Genet. 96:852-858.

Giwa, S., L.C. Abdullah, and N.M. Adam. 2010. Investigating 'Egusi' (Citrullus colocynthis L.) seed oil as potential biodiesel feedstock. Energies 3:607-618.

Guo, S., J. Zhang, H. Sun, J. Salse, W.J. Lucas, H. Zhang, Y. Zheng, L. Mao, Y. Ren, Z. Wang, J. Min, X. Guo, F. Murat, B.K. Ham, Z. Zhang, S. Gao, M. Huang, Y. Xu, S. Zhong, A. Bombarely, L.A. Mueller, H. Zhao, H. He, Y. Zhang, Z. Zhang, S. Huang, T. Tan, E. Pang, K. Lin, Q. Hu, H. Kuang, P. Ni, B. Wang, J. Liu, Q. Kou, W. Hou, X. Zou, J. Jiang, G. Gong, K. Klee, H. Schoof, Y. Huang, X. Hu, S. Dong, D. Liang, J. Wang, K. Wu, Y. Xia, X. Zhao, Z. Zheng, M. Xing, X. Liang, B. Huang, T. Lv, J. Wang, Y. Yin, H. Yi, R. Li, M. Wu, A. Levi, X. Zhang, J.J. Giovannoni, J. Wang, Y. Li, Z. Fei, and Y.Xu. 2013. The draft genome of watermelon (Citrullus lanatus) and resequencing of 20 diverse accessions. Nat. Genet. 45:51-58.

Gusmini, G., T. Wehner, and R. Jarret. 2004. Inheritance of egusi seed type in watermelon. J. Hered. 95:268-270.

Guy, J.E., E. Whittle, M. Mochec, J. Lengqvistd, Y. Lindqvista, and J. Shanklin. 2011. Remote control of regioselectivity in acyl-acyl carrier protein-desaturases. Proc. Natl. Acad. Sci. USA 108:1659416599 .

Heppard, E.P., A.J. Kinney, K.L. Stecca, and G. Miao. 1996. Developmental and growth temperature regulation of two different microsomal $w-6$ desaturase genes in soybeans. Plant Physiol. 110:311-319.

Hongtrakul, V., M.B. Slabaugh, and S.J. Knapp. 1998. DFLP, SSCP, and SSR markers for stearoyl acyl carrier protein desaturases strongly expressed in developing seeds of sunflower: Intron lengths are polymorphic among elite inbred lines. Mol. Breed. 4:195-203.

Hu, X., M. Sullivan-Gilbert, M. Gupta, and S.A. Thompson. 2006. Mapping of the loci controlling oleic and linolenic acid contents and development of FAD2 and FAD3 allele-specific markers in canola (Brassica napus L.). Theor. Appl. Genet. 113:497-507.

Huang, S., R. Li, Z. Zhang, L. Li, X. Gu, W. Fan, W.J. Lucas, X. Wang, B. Xie, P. Ni, Y. Ren, H. Zhu, J. Li, K. Lin, W. Jin, Z. Fei, G. Li, J. Staub, A. Kilian, E.A.G. van der Vossen, Y. Wu, J. Guo, J. He, Z. Jia, Y. Ren, G. Tian, Y. Lu, J. Ruan, W. Qian, M. Wang, Q. Huang, B. Li, Z. Xuan, J. Cao, A.Z. Wu, J. Zhang, Q. Cai, Y. Bai, B. Zhao, Y. Han, Y. Li, X. Li, S. Wang, Q. Shi, S. Liu, W.K. Cho, J. Kim, Y. Xu, K. Heller-Uszynska, H. Miao, Z. Cheng, S. Zhang, J. Wu, Y. Yang, H. Kang, M. Li, H. Liang, X. Ren, Z. Shi, M. Wen, M. Jian, H. Yang, G. Zhang, Z. Yang, R. Chen, S. Liu, J. Li, L. Ma, H. Liu, Y. Zhou, J. Zhao, X. Fang, G. Li, L. Fang, Y. Li, D. Liu, H. Zheng, Y. Zhang, N. Qin, Z. Li, G. Yang, S. Yang, L. Bolund, K. Kristiansen, H. Zheng, S. Li, X. Zhang, H. Yang, J. Wang, R. Sun, B. Zhang, S. Jiang, J. Wang, Y. Du, and S. Li. 2009. The genome of the cucumber, Cucumis sativus L. Nat. Genet. 41:1275-1281.

Idouraine, A., E.A. Kohlhepp, C.W. Weber, W.A. Warid, and J.J. Martinez-Tellez. 1996. Nutrient constituents from eight lines of naked seed squash (Cucurbita pepo L.). J. Agr. Food Chem. 44:721-724.

International Cucurbits Genomics Initiative. 2012. Watermelon genome. 12 Oct. 2013. <http://www.icugi.org/cgi-bin/ICuGI/genome/ home.cgi?organism $=$ watermelon $\&$ ver $=1>$.
International Plant Genetic Resources Institute. 2002. Neglected and underutilized plant species: Strategic action plan of the International Plant Genetic Resources Institute. Intl. Plant Genet. Resources Inst., Rome, Italy.

Jarret, R. and I. Levy. 2012. Oil and fatty acid contents in seed of Citrullus lanatus Schrad. J. Agr. Food Chem. 60:5199-5204.

Kachroo, A., D. Fu, W. Havens, D. Navarre, P. Kachroo, and S.A. Ghabrial. 2008. Mediated pathway induces constitutive defense signaling and enhanced resistance to multiple pathogens in soybean. Mol. Plant Microbe Interact. 21:564-575.

Lee, J., K.D. Bilyeu, and J.G. Shannon. 2007. Genetics and breeding for modified fatty acid profile in soybean seed oil. J. Crop Sci. Biotechnol. 10:201-210.

Li, H., T. Zhao, Y. Wang, D. Yu, S. Chen, R. Zhou, and J. Gai. 2011. Genetic structure composed of additive QTL, epistatic QTL pairs and collective unmapped minor QTL conferring oil content and fatty acid components of soybeans. Euphytica 182:117-132.

Li, M., X. Wang, L. Su, Y. Bi, and S. Wan. 2010. Characterization of five putative acyl carrier protein (ACP) isoforms from developing seeds of Arachis hypogaea L. Plant Mol. Biol. Rpt. 28:365-372.

Liu, K.S., F. Orthoefer, and E.A. Brown. 1995. Association of seed size with genotypic variation in the chemical constituents of soybeans. J. Am. Oil Chem. Soc. 72:189-192.

Liu, P., C.M. Wang, L. Li, F. Sun, and G.H. Yue. 2011. Mapping QTLs for oil traits and eQTLs for oleosin genes in jatropha. BMC Plant Biol. 11:132.

Loukou, A., D. Gnakri, Y. Djè, A. Kippré, M. Malice, J.P. Baudoin, and I. Bi. 2007. Macronutrient composition of three cucurbit species cultivated for seed consumption in Côte d'Ivoire. Afr. J. Biotechnol. 6:529-533.

Mabaleha, M., Y. Mitei, and S. Yeboah. 2007. A comparative study of the properties of selected melon seed oils as potential candidates for development into commercial edible vegetable oils. J. Amer. Oil Chem. Soc. 84:31-36.

Meru, G. and C. McGregor. 2013. Genetic mapping of seed traits correlated with seed oil percentage in watermelon. HortScience 48:955-959.

Natarajan, P. and M. Parani. 2011. De novo assembly and transcriptome analysis of five major tissues of Jatropha curcas L. using GS FLX titanium platform of 454 pyrosequencing. BMC Genomics 12:191.

Oluba, O., Y. Ogunlowo, G. Ojieh, K. Adebisi, G. Eidangbe, and I. Isiosio. 2008. Physicochemical properties and fatty acid composition of Citrullus lanatus (egusi melon) seed oil. J. Biol. Sci. 8:814-817.

Oyenuga, V.A. and B.L. Fetuga. 1975. Some aspects of the biochemistry and nutritive value of the watermelon seed (Citrullus vulgaris, Schrad). J. Sci. Food Agr. 26:843-854.

Panthee, D., V. Pantalone, and A. Saxton. 2006. Modifier QTL for fatty acid composition in soybean oil. Euphytica 152:67-73.

Perez-Vich, B., J.M. Fernández-Martínez, M. Grondona, S.J. Knapp, and S.T. Berry. 2002. Stearoyl-ACP and oleoyl-PC desaturase genes co-segregate with quantitative trait loci underlying high stearic and high oleic acid mutant phenotypes in sunflower. Theor. Appl. Genet. 104:338-349.

Pham, A., J. Lee, J.G. Shannon, and K.D. Bilyeu. 2010. Mutant alleles of FAD2-1A and FAD2-1B combine to produce soybeans with the high oleic acid seed oil trait. BMC Plant Biol. 10:195.

Prothro, J., K. Sandlin, R. Gill, E. Bachlava, V. White, S. Knapp, and C. McGregor. 2012. Mapping of the egusi seed trait locus (eg) and quantitative trait loci associated with seed oil percentage in watermelon. J. Amer. Soc. Hort. Sci. 137:311-315.

Ravi, K., V. Vadez, S. Isobe, R. Mir, Y. Guo, S. Nigam, M. Gowda, T. Radhakrishnan, D. Bertioli, S. Knapp, and R. Varshney. 2011. Identification of several small main-effect QTLs and a large number of epistatic QTLs for drought tolerance related traits in groundnut (Arachis hypogaea L.). Theor. Appl. Genet. 122:1119-1132.

Ren, Y., H. Zhao, Q. Kou, J. Jiang, S. Guo, H. Zhang, W. Hou, X. Zou, H. Sun, G. Gong, A. Levi, and Y. Xu. 2012. A high resolution genetic 
map anchoring scaffolds of the sequenced watermelon genome. Public Library Sci. One 7:e29453.

Rieseberg, L.H., M.A. Archer, and R.K. Wayne. 1999. Transgressive segregation, adaptation and speciation. Heredity 83:363-372.

Robinson, R.W. and D. Decker-Walters. 1997. Cucurbits. CAB Intl., Wallingford, UK.

Ruddle, P., R. Whetten, A. Cardinal, R.G. Upchurch, and L. Miranda. 2013. Effect of a novel mutation in a stearoyl-ACPdesaturase on soybean seed oil composition. Theor. Appl. Genet. 126:241-249.

Sandlin, K., J. Prothro, A. Heesacker, N. Khalilian, R. Okashah, W. Xiang, E. Bachlava, D. Caldwell, D. Seymour, V. White, E. Chan, G. Tolla, C. White, D. Safran, E. Graham, S. Knapp, and C. McGregor. 2012. Comparative mapping in watermelon [Citrullus lanatus (Thunb.) Matsum. et Nakai]. Theor. Appl. Genet. 125:1603-1618.

Shanklin, J., C. Mullins, and C. Somerville. 1991b. Sequence of a complementary DNA from Cucumis sativus L. encoding the stearoyl-Acyl-Carrier Protein desaturase 1. Plant Physiol. 97:467468.

Shanklin, J. and C. Somerville. 1991a. Stearoyl-acyl-carrier-protein desaturase from higher plants is structurally unrelated to the animal and fungal homologs. Proc. Natl. Acad. Sci. USA 88: 2510-2514.

Sharma, R., R.A. Aggarwal, R. Kumar, T. Mohapatra, and R. Sharma. 2002. Construction of an RAPD linkage map and localization of QTLs for oleic acid level using recombinant inbreds in mustard (Brassica juncea). Genome 45:467-472.

Silva, L.D., S. Wang, and Z.B. Zeng. 2012. Composite interval mapping and multiple interval mapping: Procedures and guidelines for using windows QTL Cartographer. Quantitative trait loci (QTL). Methods Protocols 871:75-119.

Tanhuanpaa, P., J. Vilkki, and M. Vihinen. 1998. Mapping and cloning of FAD2 gene to develop allele-specific PCR for oleic acid in spring turnip rape (Brassica rapa ssp. oleifera). Mol. Breed. 4:543-550.

Voorrips, R.E. 2002. MapChart: Software for the graphical presentation of linkage maps and QTLs. J. Hered. 93:77-78.
Wang, S., C.J. Basten, and Z.B. Zeng. 2011a. Windows QTL Cartographer 2.5. Dept. Statistics, North Carolina State Univ., Raleigh, NC. Wang, Y., X. Sun, Y. Zhao, F. Kong, Y. Guo, G. Zhang, Y. Pu, K. Wu, and S. Li. 2011b. Enrichment of a common wheat genetic map and QTL mapping for fatty acid content in grain. Plant Sci. 181:65-75. Wassom, J.J., V. Mikkelineni, M.O. Bohn, and T.R. Rocheford. 2008. QTL for fatty acid composition of maize kernel oil in Illinois High Oil× B73 backcross-derived lines. Crop Sci. 48:69-78.

Wills, D.M., H. Abdel-Haleem, S.J. Knapp, and J.M. Burke. 2010. Genetic architecture of novel traits in the hopi sunflower. J. Hered. 101:727-736.

XinYou, Z., Z. ShuiJin, H. SuoYi, X. Jing, L. Hua, T. FengShou, D. WenZhao, Z. XiuWang, and Z. ZhongXin. 2011. Inheritance of fat and fatty acid compositions in peanut (Arachis hypogaea L.). Agr. Sci. Technol. 12:943-946.

Yang, X., Y. Guo, J. Yan, J. Zhang, T. Song, T. Rocheford, and J.S. Li. 2010. Major and minor QTL and epistasis contribute to fatty acid compositions and oil concentration in high-oil maize. Theor. Appl. Genet. 120:665-678.

Yin, D., Y. Wang, X. Zhang, H. Li, X. Lu, J. Zhang, W. Zhang, and S. Chen. 2013. De novo assembly of the peanut (Arachis hypogaea) seed transcriptome revealed candidate unigenes for oil accumulation pathways. PLoS One 8:e73767.

Yu, S., L. Pan, Q. Yang, P. Min, Z. Ren, and H. Zhang. 2008. Comparison of the 12 fatty acid desaturase gene between high-oleic and normal-oleic peanut genotypes. J. Genet. Genomics 35:679-685.

Zhang, J. 1996. Breeding and production of watermelon for edible seed in China. Cucurbit Genet. Coop. Rpt. 19:66-67.

Zhang, P., J.W. Burton, R.G. Upchurch, E. Whittle, J. Shanklin, and R.E. Dewey. 2008. Mutations in a $\Delta 9$-stearoyl-ACP-desaturase gene are associated with enhanced stearic acid levels in soybean seeds. Crop Sci. 48:2305-2313.

Zhao, J., Z. Dimov, H.C. Becker, W. Ecke, and C. Mollers. 2008. Mapping QTL controlling fatty acid composition in a doubled haploid rapeseed population segregating for oil content. Mol. Breed. 21:115-125. 
Supplemental Table 1. Chromosomal (Chr) placement of genes encoding enzymes involved in fatty acid biosynthesis in watermelon and their homology (E-value) to corresponding genes in other plant species (Guo et al., 2013; International Cucurbits Genomics Initiative, 2012).

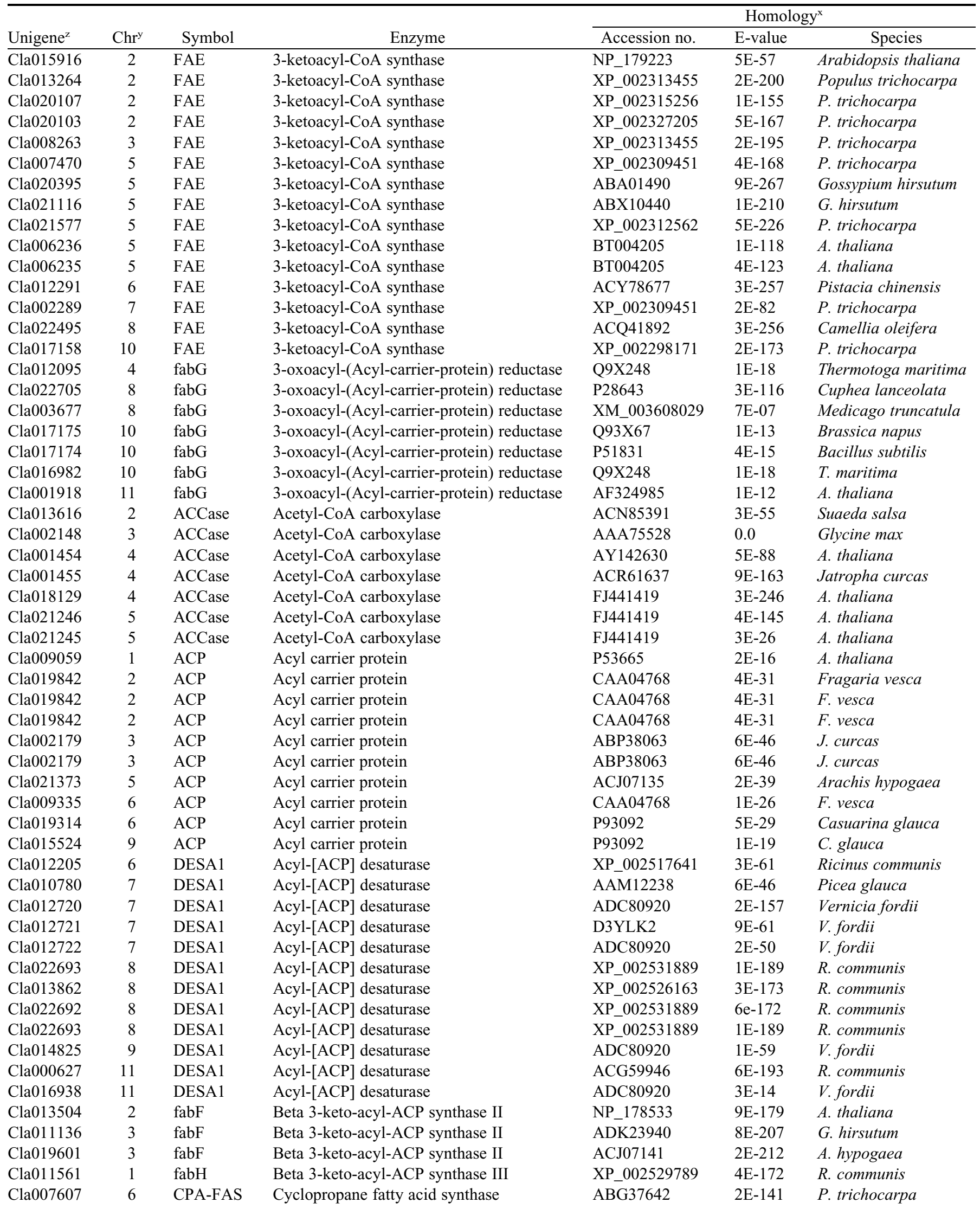


Supplemental Table 1. Continued.

\begin{tabular}{|c|c|c|c|c|c|c|}
\hline \multirow[b]{2}{*}{ Unigene $^{\mathrm{z}}$} & \multirow[b]{2}{*}{$\mathrm{Chr}^{\mathrm{y}}$} & \multirow[b]{2}{*}{ Symbol } & \multirow[b]{2}{*}{ Enzyme } & \multicolumn{3}{|c|}{ Homology $y^{x}$} \\
\hline & & & & Accession no. & E-value & Species \\
\hline Cla007608 & 6 & CPA-FAS & Cyclopropane fatty acid synthase & AAT74602 & $4 \mathrm{E}-20$ & G. hirsutum \\
\hline Cla007609 & 6 & CPA-FAS & Cyclopropane fatty acid synthase & NM_113256 & 0.0 & A. thaliana \\
\hline Cla001981 & 9 & CPA-FAS & Cyclopropane fatty acid synthase & AAT74602 & $3 \mathrm{E}-16$ & G. hirsutum \\
\hline Cla001982 & 9 & CPA-FAS & Cyclopropane fatty acid synthase & ABG37642 & $6 \mathrm{E}-12$ & P. trichocarpa \\
\hline Cla014934 & 9 & FATA & Fatty acyl-ACP thioesterase A & AAB51523 & $2 \mathrm{E}-144$ & Garcinia mangostana \\
\hline Cla003904 & 1 & FATB & Fatty acyl-ACP thioesterase A & XP_002526311 & $5 \mathrm{E}-150$ & R. communis \\
\hline Cla002633 & 3 & FATB & Fatty acyl-ACP thioesterase A & XP_002511148 & 4E-61 & R. communis \\
\hline Cla012316 & 6 & FATB & Fatty acyl-ACP thioesterase A & XP_002515564 & $1 \mathrm{E}-183$ & R. communis \\
\hline Cla015415 & 9 & FATB & Fatty acyl-ACP thioesterase A & $\mathrm{ABI} 20760$ & $6 \mathrm{E}-21$ & G. $\max$ \\
\hline Cla016747 & 11 & FATB & Fatty acyl-ACP thioesterase A & $\mathrm{ABC} 47311$ & $6 \mathrm{E}-171$ & Populus tomentosa \\
\hline Cla003201 & 2 & FAD2 & Omega- 6 fatty acid desaturase & AAO37752 & $5 \mathrm{E}-194$ & Trichosanthes kirilowii \\
\hline Cla003200 & 2 & FAD2 & Omega- 6 fatty acid desaturase & AAT72296 & $8 \mathrm{E}-146$ & Nicotiana tabacum \\
\hline Cla018729 & 6 & FAD2 & Omega- 6 fatty acid desaturase & ABU96742 & $6 \mathrm{E}-206$ & J. curcas \\
\hline Cla017539 & 10 & FAD2 & Omega- 6 fatty acid desaturase & AAS19533 & $4 \mathrm{E}-213$ & Cucurbita pepo \\
\hline Cla003659 & 1 & PPT & Palmitoyl-protein thioesterase & AK317387 & $1 \mathrm{E}-82$ & A. thaliana \\
\hline Cla003660 & 1 & PPT & Palmitoyl-protein thioesterase & ACG35638 & $7 \mathrm{E}-115$ & Zea mays \\
\hline Cla005617 & 10 & PPT & Palmitoyl-protein thioesterase & ВТ020483 & $6 \mathrm{E}-81$ & A. thaliana \\
\hline
\end{tabular}

${ }^{\mathrm{z}}$ Unigene assigned in the draft watermelon genome (Guo et al., 2013; Ren et al., 2012).

${ }^{\mathrm{y}}$ Chromosome in the draft watermelon genome sequence (Guo et al., 2013; Ren et al., 2012).

${ }^{x}$ Homology to sequences in Genbank, Swiss-Prot, TrEMBL, and TAIR (International Cucurbits Genomics Initiative, 2012). 